\title{
Predicting Student Misbehavior, Responsibility and Distraction from Schoolwork from Classroom Management Techniques: The Students' Views
}

\author{
Van Dat $\operatorname{Tran}^{1}$ \\ ${ }^{1}$ Research and International Relations Office, An Giang University, Vietnam \\ Correspondance: Van Dat Tran, Research and International Relations Office, An Giang University, Vietnam. Tel: \\ 84-76-256-565 (1714).E-mail: tvdat@agu.edu.vn
}

Received: September 15, 2015

Accepted: September 26, 2015

Online Published: October 5, 2015

doi:10.5430/ijhe.v4n4p178

URL: http://dx.doi.org/10.5430/ijhe.v4n4p178

\begin{abstract}
This study reports students' perceptions of the classroom management techniques utilized in fourteen classrooms at eight junior high schools in one province in Vietnam. It examines data from 498 students in fifteen high schools in one district in Vietnam in grades 10 to 12 to identify how teachers' use of various management techniques, and the extent to which these relate to outcome variables - student misbehavior, responsibility and distraction from schoolwork. The results indicate that Vietnamese teachers use least punishment and aggression, and most discussion, recognition, and hinting. The results obtained from multiple regression analyses also show that techniques of the classroom management as predictors of student misbehavior, responsibility and distraction from schoolwork. Of the five classroom management techniques investigated, students' perceptions of teachers' use of punishment, aggression, discussion, and recognition had the most powerful effect on outcome variables. Among school management techniques, punishment and aggression negatively related to student responsibility, while discussion, recognition, and hinting positively related to student misbehavior and distraction from schoolwork. Implications of these findings are discussed.
\end{abstract}

Keywords: Classroom management techniques, Student misbehavior, Responsibility, Distraction from schoolwork

\section{Introduction}

One of the major aims of schools in various countries is to use effective management techniques to increase the personal and communal responsibility of students, and to decrease student misbehavior, and distraction from schoolwork (Anderson, Avery, Pederson, Smith, \& Sullivan, 1997; Kennedy, 1996). There are two independent reasons, to ensure responsible behavior of students in classrooms. According to Lewis (2001),

One purpose of classroom discipline is to establish order, to permit teachers to instruct students in the formal curriculum of the school..... A second purpose is to provide an appropriate educational experience to shape the students' values and to teach them about the rights of individuals (p.1207).

In the settings of Vietnamese secondary schools, student misbehavior and school violence, two serious problems have been on the rise (Ministry of Education and Training (Ministry of Education and Training [MOET], 2010). Although Vietnamese students are expected to learn about the rights and responsibilities of citizens, respect the teacher's authority, and concern themselves with the rights of others (National Assembly of the Socialist Republic of Vietnam [NRSRV], 2008), the increasing frequency of student misbehavior and school violence has been a serious concern for educators. The data provided by MOET (2010) show that there were about 16,000 incidents of classroom misbehavior (e.g., dishonesty and disrespect for traditional authority figures), and school violence (e.g., cruelty to peers, bigotry and hate crime), which occurred in Vietnamese junior high schools between 2009 and 2010. However, very few studies have systematically investigated the relationships between different types of management techniques and student behavior in Vietnamese classrooms. Thus, the present study is the first attempt to investigate Vietnamese students' perceptions of their teachers 'management strategies and their own behavior, as well as assessing the extent of the students' responsibility in 14 classrooms at 8 junior high schools in one province in Vietnam. This study may provide Vietnamese teachers with useful information to choose the most suitable classroom management techniques for decreasing student misbehavior, and student distraction from schoolwork, and increasing student responsibility in learning. 
In recent years, studies involving the effects of classroom management strategies on a range of factors, including levels of student responsibility, misbehavior in classes, and distraction from schoolwork have emerged as an internationally important area of social science research among researchers (Roache \& Lewis, 2011; Romi, Lewis \& Katz, 2009).

In a study into the perceptions of 592 Primary students and 2938 Secondary students in Australia, Lewis (2001) reports that

More responsible students are in classes where teachers involve them more in the decision making and are seen to provide more non-directive hints, recognition for good behavior and discussion with misbehaving students to allow them to understand the impact of their behavior on others and to work out how to behave better (p.312).

This study revealed that, from the view of students, the teachers were believed to be characterized by two distinct management styles. One was identified as "coercive", and included punishment and aggression (e.g. increasing levels of consequences, yelling angrily, making sarcastic comments, etc.). The other style was called "relationship based management", which comprised discussion, hints, recognition, involvement and punishment (e.g. rewarding and praising individual students for behaving well, discussing behavior issues with students, etc.). Lewis (2001) reports that

Students who receive more relationship based management are less disrupted when teachers deal with misbehavior and generally act more responsibly in that teacher' class. In contrast, the impact of coercive management appears to be more student distraction from work and less responsibility (p.315).

When teachers are sarcastic towards students, yell in anger, keep classes in, or use sexist or racist language, students feel more distracted from their work...Coercive teachers promote misbehavior, or student misbehavior promotes an aggressive response from teachers, or both... More responsible students are in classes where teachers involve them more in the decision making and are seen to provide more non-directive hints, recognition for good behavior, and discussion with misbehaving students, to allow them to understand the impact of their behavior on others and to work out how to behave better (p.312).

In a comparative study into the relationship between students' perceptions of the classroom management techniques and student misbehavior of over 748 teachers and 5521 students in Australia, China, and Israel, (Lewis, Romi, Qui \& Katz, 2005) report that

Students who reported greater levels of misbehavior were more likely to perceive aggression by teachers, although no other strategy produced statistically significant univariate results (p.737).

A recent study by Hyman and Snook (2000) also emphasizes the negative effect of harsh and punitive management techniques. They conjecture that

Unnecessarily harsh and punitive disciplinary practices against students create a climate that contributes to school violence. This issue is little recognized and scarcely researched (p.489).

The findings of the above studies reinforced those of Miller, Ferguson, and Byrne (2000), who report that teacher behavior, such as shouting all the time, unfairly blaming students, picking on kids, and being rude, may cause classroom misbehavior, and stimulate levels of student resistance misbehavior.

In sum, classroom management and student responsibility as well as misbehavior have been studied in Australia (for example, Lewis, 2001; Oswald, 1995), China (for example, Gao, 1998; Jin \& Cortazzi, 1998; Peng, 1993), and Israel (for example, Friedman, 1994; Kaplan, Gheen, \& Midgley, 2002; Romi \& Freund, 1999). However, this is the first attempt to systematically examine students' perceptions of their teachers' disciplinary strategies and their misbehavior in the setting of junior high schools in Vietnam. Lewis (2001) argued that

In establishing the possibility of a strong connection between management strategies and the development of student responsibility, this study indicates that it may be possible to have a substantial impact on students' commitment to the protection of human rights by attending to teachers' classroom disciplinary style (p.317).

It may even be argued that without changes to the management approaches utilized by some teachers the impact of instruction in democratic values may be impeded if not nullified (p.317).

Therefore, the purposes of this study are to examine students' perceptions of classroom management strategies, and report the relationship between students' perceptions of classroom management techniques and students' 
self-reported level of responsibility. It also reports students' levels of misbehavior in class, and their distraction from schoolwork when misbehavior is handled in class by their teacher.

A survey of students was conducted to answer the primary questions:

(1) How are students' perceptions of classroom management strategies?

(2) Are perceived classroom management strategies associated with students' misbehavior, distraction, and their responsibility?

\section{Methodology}

\subsection{Participants}

Information regarding students' perceptions of classroom management strategies, levels of misbehavior and distraction, as well as levels of responsible behavior and external factors was gathered from 498 junior high school students in 14 classrooms at 8 junior high schools in a large urban province in the Southwest part of Vietnam. The students ranged in grade level from Grade 10 to Grade 12 . The students were evenly distributed by gender (48.6\% were females and $51.4 \%$ males). Table 1 shows the distribution of the classrooms by grade.

Table 1. Distribution of sample by grade level

\begin{tabular}{lccccc}
\hline Level & $\mathrm{n}$ (students) & \multicolumn{2}{c}{ Gender } & $\mathrm{n}$ (classrooms) & $\mathrm{n}$ (schools) \\
\cline { 3 - 4 } & & Female & Male & & \\
\hline Grade 10 & 173 & 81 & 92 & 5 & 2 \\
Grade 11 & 187 & 106 & 89 & 5 & 3 \\
Grade 12 & 138 & 55 & 75 & 4 & 3 \\
Total & 498 & 242 & 256 & 14 & 8 \\
\hline
\end{tabular}

Note: $\mathrm{n}=498$

\subsection{Instrumentation}

\subsubsection{Measuring classroom management strategies}

A shortened, 24-item version of the 35-item questionnaire developed by Lewis (2001) was used to measure the students' perceptions of classroom management strategies. These 24 items were utilized to assess six management strategies. The strategies measured were Punishment, Recognition and Reward, Hinting, Discussion, and Aggression. Each strategy measured had four items.

The first strategy, called punishment, contained 4 items (Gives out consequences to students who misbehave (e.g. move seats, detention); Increases the level of consequence if students will not do the right thing (e.g. move seats, detention); Increases the level of consequence if a misbehaving student argues; and Increases the level of consequence if a misbehaving student stops when told, but then does it again). The second strategy, called recognition and rewards, consisted of 4 items (Rewards the class when students behave well; Rewards individual students who behave properly; Praises individual students for good behavior; and Praises the class for good behavior). The third strategy, called hinting, comprised 4 items (Describes what students are doing wrong, and expect them to stop; Asks students questions like "What are you doing?" to get them think about how to behave better; Reminds misbehaving students about the class rules; and Describes how students are misbehaving to make them decide whether to stop or not). The fourth strategy, called discussion, contained 4 items (Discusses students' behavior with them to allow them to figure out a better way to behave in future; Lets students talk about their side of things so that it can be clearly understood; Gets students to understand why their behavior is a problem for others by discussing it with them; and Gets students to change the way they behave by helping them understand how their behavior affects others). The final strategy, called aggression, consisted of 4 items (Yells angrily at students who misbehave; Deliberately embarrasses students who misbehave; Keeps the class in because some students misbehave; and Makes sarcastic comments to students who misbehave). Each item required a response on a 5-point scale to indicate how frequently the teacher acted in such a manner "when trying to deal with misbehavior". The response alternatives for each item were "Nearly all the time, Most of the time, Some of the time, Hardly ever, and Never" and were coded from 5 to 1 , respectively. The students' responses $(n=498)$ to the five scales were checked for internal consistency by computing respective Cronbach Alpha coefficients. Table 2 describes the means, standard deviations, and alpha coefficient of these six scales. 


\subsubsection{Measuring students' misbehavior}

In order to see the level of misbehavior, 2 questions regarding student misbehavior (Lewis, 2001) were used. The first asked students to indicate how often they misbehaved in this teacher's class. This question used a 4-point scale, Often, Sometimes, Only a little and Almost never, coded from 4 to 1 . The second asked, on a 4-point scale (Nearly all, Many, Some and Hardly/None, coded 4 to 1 respectively), "How many of the students in your class misbehave? Table 2 describes the means, and standard deviations of these two questions.

\subsubsection{Measuring student distraction}

Table 2. Means, standard deviation (SD), and alpha coefficient ( $\alpha$ ) of independent and dependent variables

\begin{tabular}{|c|c|c|c|c|}
\hline Measure & Mean & SD & Alpha $(\alpha)$ & No. Items \\
\hline \multicolumn{5}{|l|}{ Independent variables } \\
\hline Punishment & 3.13 & 0.40 & 0.74 & 4 \\
\hline Recognition and reward & 3.94 & 0.54 & 0.69 & 4 \\
\hline Hinting & 4.01 & 0.51 & 0.67 & 4 \\
\hline Discussion & 3.97 & 0.45 & 0.77 & 4 \\
\hline Aggression & 3.19 & 0.47 & 0.79 & 4 \\
\hline \multicolumn{5}{|l|}{ Dependent variables } \\
\hline Personal responsibility & 3.89 & 0.52 & 0.81 & 7 \\
\hline Communal responsibility & 3.44 & 0.45 & 0.84 & 10 \\
\hline Misbehave [own] & 3.06 & 0.56 & $\mathrm{n} / \mathrm{a}$ & 1 \\
\hline Misbehave [class] & 3.54 & 0.43 & $\mathrm{n} / \mathrm{a}$ & 1 \\
\hline Distracted by management & 3.32 & 0.55 & 0.72 & 6 \\
\hline
\end{tabular}

Note: $\mathrm{n}=498$

To measure how students felt "distracted" when the teacher dealt with misbehavior, they were asked about the frequency with which each of the following 6-items assessed their reaction to the teacher. These items comprise a scale developed by Lewis (2001). The scale, called distraction, consisted of 6 items (Annoyed at the teacher; That my thoughts are interrupted; Put off my work; Not able to get on with my work properly; No longer interested in my work; and Sick of the teacher picking on kids). Each of the items had a 5-point scale, namely, Nearly all the time, Most of the time, Some of the time, Hardly Ever and Never, coded from 5 to 1 respectively. The students' responses $(\mathrm{n}=498)$ to this scale were checked for internal consistency by computing a Cronbach Alpha coefficient. Table 2 describes the means, standard deviations, and alpha coefficient of this scale.

\subsubsection{Measuring student responsibility}

To indicate levels of responsible behavior, a 17-item measure of student responsibility developed by Lewis (2001) was used. The first measure, called personal responsibility were designed to assess personally responsible behavior, the extent to which students in a class act to protect classmates' and teachers' rights, contained 7 items (Help people who are having trouble; Try my best to do well; Respect the property of others; Treat other students with respect; Speak respectfully to the teacher; Stay calm when disagreeing with teachers; and Help when things need to be done in class). The second scale, called communal responsibility, were designed to assess communally responsible behavior, the extent to which students in a class try to ensure that their classmates act in a way that protects rights, consisted of 10 items (Try to stop others from being sarcastic; Encourage classmates to listen to the views of other students; Encourage other students to speak up in class and have their say; Encourage classmates to keep their hands off the property of other students in the class unless they have their permission; Stop others from swearing at classmates and calling them names; Help others to do their best work; Try to see that other students in the class treat their classmates with respect; See that classmates help other students who are having trouble; Help others to stay cool rather than lose their temper with their classmates; and Try to get others to help when things need to be done).

To complete the two measures of responsible behavior, students were asked to indicate how well each of the items characterized the way they behaved. Each of the item had a 6-point scale addressing how much the item was like them, namely, Exactly like me, Very much like me, Mostly like me, A little like me, Mostly not like me and Not at all like me, coded from 6 to 1 respectively. The students' responses $(n=498)$ to the two scales were checked for internal consistency by computing respective Cronbach Alpha coefficients. Table 2 describes the means, standard deviations, and alpha coefficient of these two scales. 


\subsection{Procedure}

As stated above all of grade $10^{\text {th }}, 11^{\text {th }}$, and $12^{\text {th }}$ students from 14 classes at 4 junior high schools in An Giang, a large urban province in the Southwest part of Vietnam were invited to participate in this study after the permission for access to the study was obtained from the principals of schools and the Department of Education and Training. All participants were made aware that participation was voluntary and they were free to withdraw from the research at any time. The privacy of participants was ensured concerning the information they supplied in the questionnaires. No questions or statements required the participants to provide their names or the school where they are studying. The questionnaire focused their attention onto one of six subject areas taught (Mathematics, Physics, Chemistry, Biology, English and History). They were also required to focus on one class in that subject area and the teacher who teaches it when completing the questionnaires. Participants completed the questionnaires in 50 minutes. The first author personally collected the completed questionnaires from the head teachers of classes in each school. The response rate for schools was very high (96\%). This is consistent with the level of concern about issues of classroom management, misbehavior, distraction and responsibility at this school level.

\subsection{Data analysis}

To investigate students' perception of classroom management strategies, descriptive statistics were performed. The relationships among predictor variables - techniques of classroom management, and outcome variables misbehavior, distraction and responsibility were investigated using the Pearson product-moment correlation coefficient. Also, multiple regression analyses were conducted to determine if there were any associations among predictor variables and outcome variables. For all test, the significance level was determined with $\mathrm{p}<.05$.

\section{Results and discussion}

\subsection{Students' perceptions of classroom management strategies}

The first analysis addressed the first question "How are students' perceptions of classroom management strategies?" Inspection of the descriptive results in Table 2 indicates that overall, students had high perceptions of classroom management strategies used by teachers in term of hinting, recognition and reward, discussion, while students had medium perceptions of punishment, and aggression. The results show that punishment, and aggression were between "most of the time" and "some of the time" used by teachers, while students report very frequent teacher use of hinting, recognition and reward, and discussion. The technique with the highest mean is hinting $(\mathrm{M}=4.01, \mathrm{SD}=$ $0.51)$, which is followed by discussion $(\mathrm{M}=3.97, \mathrm{SD}=0.45)$, and recognition and reward $(\mathrm{M}=3.94, \mathrm{SD}=0.54)$. The techniques with the lowest mean are punishment $(\mathrm{M}=3.13, \mathrm{SD}=0.40)$, and aggression $(\mathrm{M}=3.19, \mathrm{SD}=0.47)$. The findings of this study appear consistent with those of Lewis et al., (2005), which indicate that Chinese teachers use more hinting, recognition and reward, and discussion than punishment or aggression. This relative result may be explained by the Confucian heritage in both Vietnam and China which emphasizes social order. Future studies should investigate the possible factors of why hinting, recognition and reward, and discussion are reported to be significantly high in the settings of Vietnamese education. In addition, results (Table 2) show that students acknowledge misbehaving "sometimes" in their class, and they report that some students in their class misbehave. The finding showed that, on average, students claimed to misbehave more than sometimes. This finding is consistent with previous studies (Buchanan, 2010; Chan, 2006; Davidson, 2009) which suggest that student misbehavior is a continuing, but at a low level of frequency. Inspection of the means scores shows students agree that approximately some of the times when their teacher deals with management they are distracted from learning. Inspection of the mean scores showed that students reported higher levels of personal responsibility - students' willingness to protect rights $(\mathrm{M}=3.89, \mathrm{SD}=0.52)$ than communal responsibility - encourage classmates to act responsibly $(\mathrm{M}=3.44, \mathrm{SD}$ $=0.45)$. The finding that students report more personal than communal responsibility is consistent with those of previous studies (Lewis, 2001; Lewis et al., 2005) which also indicate that students report higher levels of personal than communal responsibility.

\subsection{The relationship between management strategies and other measures}

To examine the relationship among predictor variables - classroom management techniques and outcome variables student misbehavior, responsibility, and distraction from schoolwork, correlations between each of the four management strategies and the other outcome measures were computed. Inspection of the correlations in Table 3 indicates that all of predictor variables - punishment, recognition and reward, hinting, discussion, and aggression have statistically significant correlations $(\mathrm{p}<.05)$ with outcome variables - student misbehavior, responsibility, and distraction from schoolwork. The two techniques of punishment and aggression were negatively and statistically significant related to both personal responsibility and communal responsibility scales, and positively and statistically 
significant related to misbehave (own), misbehave (class), and distracted by management. The three techniques of recognition and reward, hinting and discussion were positively and statistically significant related to both personal responsibility and communal responsibility scales, and negatively and statistically significant related to misbehave (own), misbehave (class), and distracted by management.

Table 3. The relationship between management strategies and other measures

\begin{tabular}{llcccc}
\hline \multicolumn{1}{c}{ Measure } & \multicolumn{3}{c}{ Recognition } & & \\
& Punishment & $\&$ reward & Hinting & Discussion & Aggression \\
\hline Personal responsibility & $-0.63^{* *}$ & $0.62^{* *}$ & $0.58^{* *}$ & $0.52^{* *}$ & $-0.66^{* *}$ \\
Communal Responsibility & $-0.59^{* *}$ & $0.50^{* *}$ & $0.45^{* *}$ & $0.48^{* *}$ & $-0.57^{* *}$ \\
Misbehave [own] & $0.49^{* *}$ & $-0.51^{* *}$ & $-0.39^{* *}$ & $-0.60^{* *}$ & $0.61^{* *}$ \\
Misbehave [class] & $0.32^{*}$ & $-0.29^{*}$ & $-0.33^{*}$ & $-0.32^{*}$ & $0.67^{* *}$ \\
Distracted by management & $0.27^{*}$ & $-0.26^{*}$ & $-0.37^{*}$ & $-0.27^{*}$ & $0.58^{* *}$ \\
\hline
\end{tabular}

**. Correlation is significant at the 0.01 level (2-tailed).

*. Correlation is significant at the 0.05 level (2-tailed).

Table 4 reports the results of the two multiple regression analyses on the predicted measures and dependent variables. The first model reports the results of multiple regression analyses performed to predict students' personal responsibility. This model with all five predictors explained 50 percent of the variance in personal responsibility scale $\left(\mathrm{R}^{2}=.497\right), F=48.452, \mathrm{p}<.001$. All of five variables of classroom management predicted personal responsibility scale. The two techniques of classroom management were negatively and statistically significant related to personal responsibility scale, with the beta value of aggression $(\beta=-.372)$, and punishment $(\beta=-.343)$. The three techniques of classroom management were positively and statistically significant related to personal responsibility scale, with the beta value of recognition and reward $(\beta=.351)$, discussion $(\beta=.306)$, and hinting $(\beta$ $=.267$ ). The results show that the aggression, recognition and reward, punishment, and discussion techniques were the strongest predictors of students' personal responsibility while the hinting technique was the weakest predictor. Similarly, the second model reports the results of regression analyses performed to predict students' communal responsibility from classroom management techniques. This model with all five predictors produced 42 percent of the variance in communal responsibility scale $\left(\mathrm{R}^{2}=.421\right), F=41.272, \mathrm{p}<.001$. All of five variables of classroom management predicted communal responsibility scale. The two techniques of classroom management were negatively and statistically significant related to communal responsibility scale, with the beta value of aggression $(\beta$ $=-.427)$, and punishment $(\beta=-.401)$. The three techniques of classroom management were positively and statistically significant related to communal responsibility scale, with the beta value of recognition and reward ( $\beta$ $=.373)$, discussion $(\beta=.307)$, and hinting $(\beta=.214)$. The results show that the aggression, punishment, recognition and reward, and discussion techniques were the strongest predictors of students' personal responsibility while the hinting technique was the weakest predictor.

Table 4. Results from multiple regression analyses on personal and communal responsibility scales

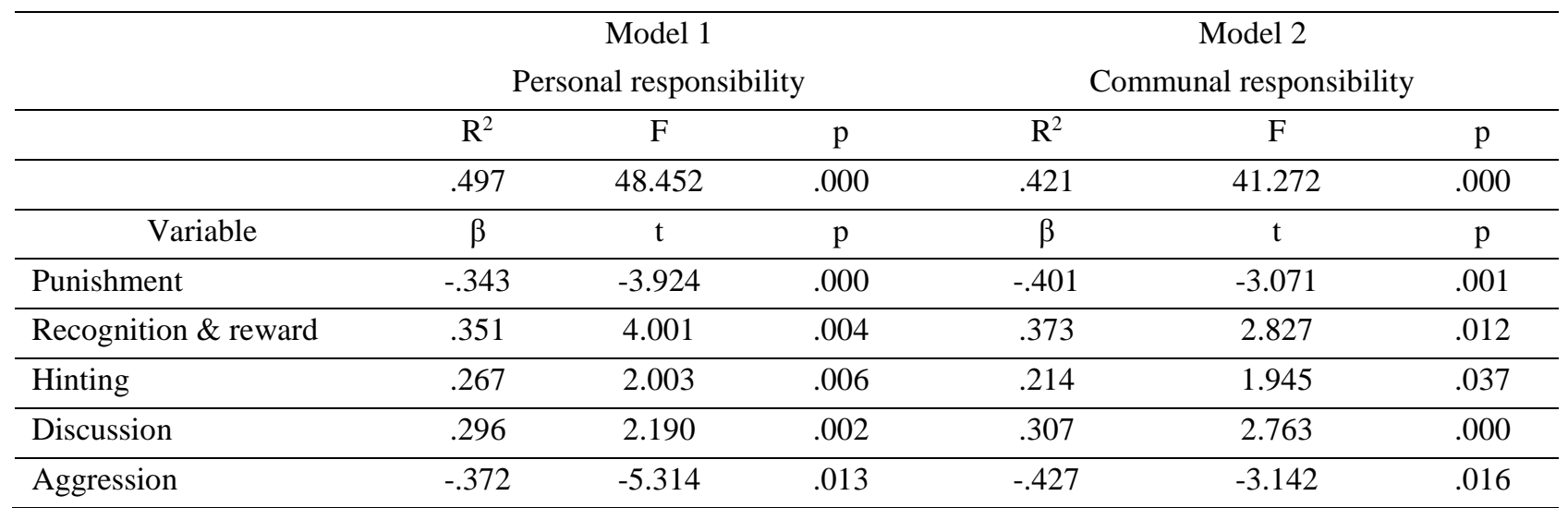

a. Predictors: punishment, recognition \& reward, hinting, discussion, and aggression

b. Dependent variables: personal and communal responsibility

${ }^{*} \mathrm{p}<.05$ 
Table 5 reports the results of the two multiple regression analyses on the predicted measures and dependent variables. The third model reports the results of multiple regression analyses performed to predict students' misbehave (own). This model with all five predictors explained 47 percent of the variance in misbehave (own) scale $\left(\mathrm{R}^{2}=.471\right), F=$ $36.214, \mathrm{p}<.001$. All of five variables of classroom management predicted misbehave (own) scale. The two techniques of classroom management were positively and statistically significant related to misbehave (own) scale, with the beta value of aggression $(\beta=.431)$, and punishment $(\beta=.401)$. The three techniques of classroom management were negatively and statistically significant related to misbehave (own) scale, with the beta value of recognition and reward $(\beta=-.424)$, discussion $(\beta=-.423)$, and hinting $(\beta=-.367)$. The results show that the aggression, recognition and reward, punishment, and discussion techniques were the strongest predictors of students' misbehave (own) while the hinting technique was also the weakest predictor. Similarly, the fourth model reports the results of regression analyses performed to predict students' misbehave (class) from classroom management techniques. This model with all five predictors produced 36 percent of the variance in misbehave (class) scale $\left(\mathrm{R}^{2}\right.$ $=.364), F=34.519, \mathrm{p}<.001$. All of five variables of classroom management predicted misbehave (class) scale. The two techniques of classroom management were positively and statistically significant related to misbehave (class) scale, with the beta value of aggression $(\beta=.364)$, and punishment $(\beta=.312)$. The three techniques of classroom management were negatively and statistically significant related to misbehave (class) scale, with the beta value of discussion $(\beta=-.327)$, recognition and reward $(\beta=-.262)$, and hinting $(\beta=-.214)$. The results show that the aggression, punishment, recognition and reward, and discussion techniques were also the strongest predictors of students' misbehave (class) while the hinting technique was also the weakest predictor.

Table 5. Results from multiple regression analyses on misbehave (own) and misbehave (class) scales

\begin{tabular}{lcccccc}
\hline & \multicolumn{3}{c}{$\begin{array}{c}\text { Model 3 } \\
\text { Misbehave (own) }\end{array}$} & \multicolumn{3}{c}{$\begin{array}{c}\text { Model 4 } \\
\text { Misbehave (class) }\end{array}$} \\
\hline \multicolumn{1}{c}{ Variable } & $\mathrm{R}^{2}$ & $\mathrm{~F}$ & $\mathrm{p}$ & $\mathrm{R}^{2}$ & $\mathrm{~F}$ & $\mathrm{p}$ \\
\hline Punishment & .471 & 36.214 & .000 & .364 & 34.519 & .000 \\
\hline Recognition \& reward & \multicolumn{1}{c}{.401} & 3.917 & .017 & .312 & 2.123 & .011 \\
\hline Hinting & -.424 & -4.914 & .000 & -.262 & -2.640 & .022 \\
\hline Discussion & -.367 & -3.004 & .012 & -.214 & -1.976 & .004 \\
\hline Aggression & -.423 & -4.900 & .003 & -.327 & -2.431 & .017 \\
\hline
\end{tabular}

a. Predictors: punishment, recognition \& reward, hinting, discussion, and aggression

b. Dependent variables: misbehave (own) and misbehave (class)

* $\mathrm{p}<.05$

Table 6. Results from multiple regression analyses on distracted by management scale

\begin{tabular}{lccc}
\hline & & \multicolumn{2}{c}{ Model 5 } \\
& \multicolumn{1}{c}{ Distracted by management } & \\
\hline \multicolumn{1}{c}{ Variable } & $\mathrm{R}^{2}$ & $\mathrm{~F}$ & $\mathrm{p}$ \\
\hline Punishment & .371 & 43.210 & .000 \\
\hline Recognition \& reward & $\beta$ & $\mathrm{t}$ & $\mathrm{p}$ \\
\hline Hinting & .378 & 3.642 & .000 \\
\hline Discussion & -.264 & -2.730 & .024 \\
\hline Aggression & -.172 & -2.001 & .007 \\
\hline a. Prediots & -.274 & -3.067 & .000 \\
\hline
\end{tabular}

a. Predictors: punishment, recognition \& reward, hinting, discussion, and aggression

b. Dependent variable: distracted by management

* $\mathrm{p}<.05$ 
Table 6 reports the results of the multiple regression analysis on the predicted measures and dependent variables. The final model reports the results of multiple regression analyses performed to predict students' distracted by management. This model with all five predictors explained 37 percent of the variance in distracted by management scale $\left(\mathrm{R}^{2}=.371\right), F=43.210, \mathrm{p}<.001$. All of five variables of classroom management predicted distracted by management scale. The two techniques of classroom management were positively and statistically significant related to distracted by management scale, with the beta value of aggression $(\beta=.416)$, and punishment $(\beta=.378)$. The three techniques of classroom management were negatively and statistically significant related to distracted by management scale, with the beta value of discussion $(\beta=-.274)$, recognition and reward $(\beta=-.264)$, and hinting $(\beta=$ -.172). The results show that the aggression, punishment, discussion, and recognition and reward techniques were the strongest predictors of students' distracted by management while the hinting technique was also the weakest predictor.

The results indicated that teachers' classroom management had both positively and negatively significant influences on the outcome variables - student personal and communal responsibility, misbehave (own) and misbehave (class), and distraction from schoolwork. The finding shows that students closely associated with teachers' classroom management techniques, and students are influenced directly by their perceptions of classroom management techniques, and this affects their personal and communal responsibility, misbehave (own) and misbehave (class), and distraction from schoolwork. Of the classroom management techniques in the models, students' perceptions of all classroom management techniques predicted student outcomes - responsibility, misbehave, and distraction. The results show that students with higher perceptions of classroom management in terms of aggression and punishment had lower responsibility, while students who perceived better recognition and reward, discussion, and hinting techniques reported greater responsibility. The strongest predictor of student responsibility was aggression, followed by punishment, recognition and reward, and discussion, while the weakest predictor was the hinting. In addition, the results show that students with higher perceptions of classroom management in terms of aggression and punishment had greater misbehave, and distraction from schoolwork, while students who perceived higher recognition and reward, discussion, and hinting techniques reported lower misbehave, and distraction from schoolwork. The strongest predictor of student misbehavior, and distraction from schoolwork was aggression, followed by punishment, recognition and reward, and discussion, while the weakest predictor was also the hinting. The findings highlight that techniques of classroom management play an important role for junior high school students' responsibility.

It could be argued that teachers who make sarcastic comments to misbehaving students, yell angrily at them, embarrass students or keep the class in, as they deal with misbehavior, make students feel more distracted from their learning. It could also be argued that students feel more disrupted by teachers who punish students who misbehave (e.g. move their seats, detention), and increase the level of consequences. The results indicated that coercive teachers who use consequences promote misbehavior or those teachers facing more misbehavior use more punishment and aggression. It can be seen that more responsible students are in classes where teachers reward the class when students behave well, reward individual students who behave properly and praise individual students and the class for behaving well. The relationship between disciplinary techniques and student responsibility reported in this study show that more responsible students have teachers who are seen as more likely to recognize appropriate behavior. It may be argued that the greater use of recognition has resulted in more student responsibility or alternatively more responsible student behavior elicits greater recognition by teachers. The data from this study also show that the use of aggression and punishment are a result of more student misbehavior or cause it. The findings that greater use by teachers of aggression and punishment are seen by students as a factor distracting them from their work may provide support for the contention that these techniques may lead to more off task behavior by students. In general the results discussed above indicate that some teachers' management techniques may bring about greater responsibility in students, whereas others may cause more distraction from schoolwork and misbehavior. In Vietnamese classrooms, where students are called to learn about the rights and responsibilities of citizenship, and respect for the teacher's authority, and caring for the rights of others (NASRV, 2008), teachers may make greater use of recognition to promote student responsibility. In addition, there is little need for recourse to aggression and excessive punishment in Vietnamese classrooms because students who are more responsible do not confront teachers' authority. The results of this study are consistent with the findings of the previous research studies (Hyman \& Snook, 2000; Miller et al., 2000; Lewis, 2001; Lewis et al., 2005) which also indicate that the greater use of recognition results in more student responsibility, and student distraction from schoolwork and misbehavior were results of punishment and aggression. 


\section{Conclusion}

The findings of this study indicate that Vietnamese teachers in the fifteen schools studied increased their use of recognition and reward, discussion, and hinting to react to classroom misbehavior. We know from previous studies that in general, Vietnamese classrooms are seen as having most recognition and least punishment, and aggression. Misbehavior in classes relates to the greater use of punishment and aggression. Hyman and Snook (2000) found common ground in the effect of management techniques on students' ability to construct appropriate democratic values in classrooms, and wrote that

Teachers in democratic classrooms emphasize cooperation, mutual goal setting, and shared responsibility. Students behave because it is the right thing to do and because they respect the rights of others (p.495).

The results of the study show that Vietnamese teachers should be encouraged to minimize the level of student misbehavior and student distraction from schoolwork by decreasing their use of aggressive disciplinary techniques such as aggression and the punishment of students who misbehave and should increase levels of recognition and rewarding of appropriate behavior, as well as increasing levels of discussion with students. The study also shows that the forms of recognition or some of the rewards help students increase student responsibility and respect for the rights of others. Teachers should recognize and reward positive students and class behavior, which may build positive relationships between students and students. Such positive relationships may help construct the trustful and respectful environment in which levels of student misbehavior may be significantly minimized (Lewis, 1997).

\section{References}

Anderson, C., Avery, P. G., Pederson, P. V., Smith, E. S., \& Sullivan, J. L. (1997). Divergent perspectives on citizenship education: A Q-method study and survey of social studies teachers. American Educational Research Journal, 34(2), 333-364. http://dx.doi.org/10.3102/00028312034002333

Birch, S. H., \& Ladd, G. W. (1998). Children's interpersonal behaviors and the teacher-child relationship. Developmental Psychology, 34, 934-946. http://dx.doi.org/10.1037/0012-1649.34.5.934

Buchanan, J. (2010). May I be excused? Why teachers leave the profession. Asia Pacific Journal of Education, 30, 199-211. http://dx.doi.org/10.1080/02188791003721952

Chan, D. W. (2006). Emotional intelligence and components of burnout among Chinese secondary school teachers in Hong Kong. Teaching and Teacher Education, 22, 1042-1054. http://dx.doi.org/10.1016/j.tate.2006.04.005

Davidson, K. V. (2009). Challenges contributing to teachers stress and Burnout. Southeastern Teacher Educational Teacher, 2, 47-56.

Friedman, I. A. (1994). Conceptualizing and measuring teacher-perceived student behaviors: Disrespect, sociability and attentiveness. Educational and Psychological Measurement, 54(4), 949-958. http://dx.doi.org/10.1177/0013164494054004011

Gao, L. (1998). Cultural context of school science teaching and learning in the People's Republic of China. Science Education, 82, 1-13. http://dx.doi.org/10.1002/(SICI)1098-237X(199801)82:1<1::AID-SCE1>3.0.CO;2-L

Hammarberg, A., \& Hagekull, B. (2006). Changes in externalizing and internalizing behaviors over a school-year: differences between 6-year-old boys and girls. Infant and Child Development, 15, 123-137. http://dx.doi.org/10.1002/icd.444

Henricsson, L., \& Rydell, A. M. (2004). Elementary School Children with Behavior Problems: Teacher-Child Relations and Self-Perception. A Prospective Study. Merrill-Palmer Quarterly, 50, 111-138. http://dx.doi.org/10.1353/mpq.2004.0012

Hyman, I., \& Snook, P. A. (2000). Dangerous schools and what you can do about them. Phi Delta Kaplan, 81(7), 489-501.

Jin, L., \& Cortazzi, M. (1998). Dimensions of dialogue: Large classes in China. International Journal of Educational Research, 29, 739-761. http://dx.doi.org/10.1016/S0883-0355(98)00061-5

Kaplan, A., Gheen, M., \& Midgley, C. (2002). Classroom goal structure and student discruptive behavior. British Journal of Educational Psychology, 72(2), 191-212. http://dx.doi.org/10.1348/000709902158847

Kennedy, K. J. (1996). New challenges for civics and citizenship. ACT. Australia: ACSA.

Keung, H. (2005). The relation of gender-role classifications to the prosocial and antisocial behavior of Chinese adolescents. The Journal of Generic Psychology, 166, 189-192. http://dx.doi.org/10.3200/GNTP.166.2.189-202 
Lewis, R. (1997). The Management Dilemma. The Council for Educational Research, Melbourne: ACER Press.

Lewis, R. (2001). Classroom management and student responsibility: the students' view. Teaching and Teacher Education, 17, 307-319. http://dx.doi.org/10.1016/S0742-051X(00)00059-7

Lewis, R., \& Loveggrove, M. N. (1987). What students think of teacher's classroom control techniques: Results from four studies. In J. Hastings \& J. Schwieso (Eds.), New directions in educational psychology (Vol. 2, pp. 93-113): The Palmer Press.

Lewis, R., Romi, S., Qui, X., \& Katz, Y. (2005). Teachers' classroom management and student misbehavior in Australia, China and Israel. Teaching and Teacher Education, 21, 729-741. http://dx.doi.org/10.1016/j.tate.2005.05.008

Lickona, T. (1996). Teaching respect and responsibility Reclaiming children and Youth. Journal of Emotional and Behavioral Problems, 5(3), 143-151.

Miller, A., Ferguson, E., \& Byrne, I. (2000). Pupils' caual attributions for difficult classroom behavior. Bristish Journal of Educational Psychology, 70, 85-96. http://dx.doi.org/10.1348/000709900157985

Oswald, U. (1995). Difficult to manage students: A survey of children who fail to respond to student management strategies in government schools. Educational $\quad$ Studies, $21, \quad 265-276$. http://dx.doi.org/10.1080/0305569950210208

Peng, S. S. (1993). Fostering student management and effort: Approaches used in Chinese schools. Paper presented at the Conference Name (April 12-16, 1993).

Roache, S., \& Lewis. R. (2011). Teachers' views on the impact of classroom management on student responsibility. Australian Journal of Education. 55(2); 132-146. http://dx.doi.org/10.1177/000494411105500204

Romi, S., \& Freund, M. (1999). Teachers', students' and parents' attitudes towards discruptive behavior problems in high school; a case study. Educational Psychology, 19(1), 53-70. http://dx.doi.org/10.1080/0144341990190104

Romi, S., Lewis, R., \& Katz, Y. (2009) Student responsibility and classroom discipline in Australia, China and Israel. Compare, 39(4), 439-452. http://dx.doi.org/10.1080/03057920802315916

Ministry of Education and Training (MOET). (2010). School Violence in Vietnam. http://tailieu.vn/xem-tai-lieu/de-tai-bao-luc-hoc-duong-o-viet-nam.411893.html.

National Assembly of the Socialist Republic of Vietnam [NASRV] (2008). Education Law, No. 38/2008/QH11-2008. Hanoi: Education Press. 